\title{
Culture of an inclusive educational organization as an indicator of the quality of education in a contemporary metropolis
}

\author{
Julia Shulekina ${ }^{1 *}$, Diana Novikova $^{1}$, and Madina Abayeva ${ }^{2}$ \\ ${ }^{1}$ Moscow City University, Institute of Special Education and Psychology, Speech Therapy \\ Department, Moscow, Russia \\ ${ }^{2}$ Abai Kazakh National Pedagogical University, Institute of Philology and Multilingual Education, \\ Russian Language and Literature Department, Almaty, Kazakhstan
}

\begin{abstract}
In modern realities, the design of conceptual aspects of educational inclusion is the actual research problem. The key concept for the formation of an inclusive platform of an educational organization is "organizational culture" which is understood as the result of the complex integrative interaction of the educational process participants and various learning environments created in the space of educational organizations of megacities. The purpose of the present study is to substantiate the need to support and develop organizational culture by different participants, including pupils with health limitations. This naturally removes the restrictions on any kind of support, care, and accompaniment that children with developmental disabilities can receive in an inclusive educational organization to achieve social and academic success. The review presented in the article is based on the analysis of several significant scientific and practical studies on the concerned problem. Following this goal, the article reveals the conditions for building, as well as trends in the development of an inclusive culture in educational organizations, which is necessary for the effective inclusion of the latter in a broader inclusive educational environment. The article emphasizes that different actors need different training to implement organizational culture, which significantly affects the involvement of different learning environments as an incubator in such training. The authors carried out the analysis of the Russian and Western models of organizational culture. Based on the data of foreign studies, the authors show the characteristic features of the European model of an organizational inclusive culture, as well as list the basic principles necessary to form an organizational culture included in the inclusive practice of an educational organization in the Russian Federation.
\end{abstract}

Keywords: inclusion, inclusive approach to education, educational environment.

*Corresponding author: juliah@mgpu.ru 


\section{Introduction}

Today, the main goal of education is not only developing knowledge, skills, abilities, and competencies but also relationships, as well as drawing into fundamental values [1]. Therefore, educational objectives are directly associated with the need to help young people in close cooperation with parents and families to become active, responsible, open-minded members of society [2]. In many ways, the introduction of an inclusive worldview contributes to a well-built organizational culture of an educational organization.

For the authors of the present study, it has become important to reflect the main development trends in the views on the organizational culture of an inclusive educational organization in the domestic and foreign educational traditional practice. Guided by the idea of general principles of formation and integration of organizational culture, the authors have assumed that due to the specifics of the historical formation of inclusive education in Russia, in particular, under the strong influence of correctional-oriented concepts, the understanding of concerned phenomenon at the present stage has peculiar features. The task of the present study has been exactly to identify these features.

\section{Methods}

The review was prepared using several resources, including scientific research, the Declaration on inclusive education, and Internet sites. The corpus of the studied publications included works that most fully revealed various aspects of the problem that were close to the views of the authors. The literature used in the review reflected current trends in inclusive education, which ensured the reliability and relevance of the material.

\section{Results}

During the review, the focus is made on the idea that the organizational culture of an educational organization is understood by contemporary specialists in a very diverse way. The very definition of this concept carries various key aspects. According to foreign studies, the organizational culture of an educational organization can be an effective tool of communication policy in terms of forming correct and rational relations among participants in the educational process [3-7]. Establishing appropriate relationships will allow the educational organization to successfully adapt to the external environment, establish effective and productive activities, and, most importantly, all educational process participants will feel like a single unique and special team [8].

Some researchers orient the community to the fact that the educational organization culture is a multicomponent system of key ideas, philosophical and ideological, which are fully accepted and shared by the educational process participants. Certainly, they should have common expectations, and value orientations that underlie the relationships.

Experts identify the following priority aspects in this problem area:

- understanding the building principles of an inclusive culture,

- forming, developing, and fully adopting an inclusive policy in the educational organization,

- implementing inclusive practices directly in the educational organization.

These aspects set the thought-setting vectors not only aimed at reconstructing educational organizations in the field of inclusive practice but also focused on the development of common values and relations of cooperation, including in other aspects.

A new paradigm of educational relations is built on the values of inclusive education, which determine the humanistic nature of the very education. They include the priority of 
equality, participation, cooperation in the aspect of forming an inclusive educational culture in an educational institution, as well as a positive attitude to the individual characteristics of pupils. An inclusive organizational culture, as E. Horn [9] notes, embraces everyone, making them feel valuable to the organization, and creating a sense of belonging.

Such values, integrated into the educational process at various levels of education, form the platform of the general culture of the educational organization $[6,9,10]$. For example, today, in Western practices there is a tendency for the success of schools to depend on the success of the implemented inclusive programs, when views on the school community expand, a common language and values arise, and an inclusive leader appears. This leads to the formation of inclusive school culture [11-13].

A characteristic feature of Western trends in modeling and implementing an inclusive culture of an educational organization can be considered as the orientation toward supporting positive behavior among the educational process participants [14]. According to some authors $[14,15]$, creating a positive learning environment stimulates the teacher's ability to effectively teach all children, which undoubtedly contributes to improving the academic and social success of pupils.

Special attention of the professional pedagogical community is also focused on the problem of pedagogical culture of pupils' parents who are full-fledged participants in the educational process. There is no doubt that purposeful, specially organized training of adults for the upbringing of their children can lead to a significant increase in the level of their pedagogical literacy.

In choosing educational environments that promote the development of organizational culture in general, the educational organization is guided by the principle of maximum efficiency and accessibility of means to achieve the goal, namely, involving parents of children with different abilities and needs to a single organizational culture. In this regard, the system of additional education is quite popular since it takes into account factors, such as the special features of family upbringing, voluntary classes, different age groups, and informal communication between adults and children. The freedom of choice of activity for each child, strong motivation, and a unique psychological climate make the learning and development environment comfortable [16]. Besides, this implies the need for a close partnership between the family and the child. It is through the additional education channel that parents can get the experience of joint learning and interaction not only with their child but also with different children studying in a particular inclusive educational organization, thereby orienting the child to the general culture of the educational organization, enriching and diversifying it.

As can be seen, the interpretation of the concept of "culture of an educational organization included in inclusive practice" is multifaceted. This concept includes the values and knowledge about inclusive education and support for these values; a trusting atmosphere that allows avoiding conflict and unpleasant situations; the basis for forming an understanding of the diversity of educational needs, acceptance, as well as a need for continuous improvement of inclusive practices in the educational process.

\section{Discussion}

The priorities that have developed so far in the Russian Federation in terms of understanding the organizational culture of an educational organization included in inclusive practice are listed and described briefly below:

1. A multicultural environment is an objective reality. A contemporary educational organization provides a full-fledged opportunity for education and open access to it of pupils not only with special educational needs but also with individual personal requests. 
2. Individualization and personalization of the learning process is an integral part of the educational culture in inclusive practice.

3. Forming a single style. First of all, this is a cohesive activity of different profile specialists aimed at obtaining the maximum possible successful results.

4. An inclusive culture is inherently linked to the communicative and consultative aspects of the relationship with the parent community. Parents are equal partners.

5. The expectation of success of pupils, involved in inclusive practice, is the only possible scenario for the further sequence of events. Teachers certainly believe, appreciate, and expect natural success from each of their pupils.

6. The inclusive culture of an educational organization is an unlimited resource for the social development of society and the formation of basic humanistic ideas, such as acceptance, mutual assistance, and mutual respect.

However, a review of some Russian studies [5, 17] points to the lack of preparedness of educational organizations to adopt an inclusive organizational culture as a valuable guide in the development of the general education system. This point also determines the specifics of the organizational culture model of the inclusive educational organization in Russia.

\section{Conclusion}

Active work on creating a correct culture of a contemporary inclusive educational organization, that is, meeting the needs of contemporary society, allows the latter to change for the better various aspects of its functioning. On the one hand, this involves contributing to strengthening various types of interaction among participants of the educational process in a particular educational organization and the city, region, and territory in general, while on the other hand, contributing to the social and professional integration of employees of different ages of educational organizations. These processes are closely linked to the quality of education that any educational organization in a contemporary metropolis can provide.

The present study can be considered quite promising in terms of strengthening the support of the younger generation in the ability to critically comprehend the events of the current historical period aimed at planning future success in the educational sphere.

\section{References}

1. International Baccalaureate, Access and inclusion policy (2018). Accessed on: December 20, 2020. [Online]. Available: https://resources.ibo.org/data/access-andinclusionpolicy_956444e5-7b09-43a7-ad8e-

519b88ac7ac4/PRCAccess_and_inclusion_policy-WEB_1a60fbd7-7033-4b3a-b3829737c2361b32.pdf

2. European Comission, Declaration on promoting citizenship and the common values of freedom, tolerance and non-discrimination through education (European Comission, Brussels, 2015). Accessed on: December 20, 2020. [Online]. Available:

https://ec.europa.eu/assets/eac/education/news/2015/documents/citizenship-educationdeclaration_en.pdf

3. K.G. Bagduyeva, I.A. Gadzhiyev, F.G. Gadzhiyeva, Mir nauki, kultury, obrazovaniya, 1(62), 111-112 (2017)

4. A.I. Kalashnikov, Pedagogical Education in Russia, 5, 202-208 (2014)

5. Ch.B. Kozhaliyeva, Yu.A. Shulekina, I.P. Kireyeva, Problems of modern pedagogical education, 52(3), 335-345 (2016) 
6. N.V. Starovoyt, Scientific and methodical electronic journal "Concept", 8, 31-35 (2016)

7. N.A. Todd, Support Teachers, Learning Difficulties and Secondary School Culture (2010)

8. M.A. Dyachkova, O.N. Tomyuk, A.V. Shutaleva, A.Yu. Dudchik, Perspektivy Nauki i Obrazovaniya, 5(41), 373-385 (2019). https://doi.org/10.32744/pse.2019.5.26

9. E. Horn, What is an Inclusive Culture, and Do You Have One? (NMHC, Washington, 2018). Accessed on: December 20, 2020. [Online]. Available:

https://www.nmhc.org/news/nmhc-news/what-is-an-inclusive-culture-and-do-youhave-one/

10. P. Angelides, M. Ainscow, School Effectiveness and School Improvement, 11(2), 145163 (2000). https://doi.org/10.1076/0924-3453(200006)11:2;1-q;ft145

11. R. Dorczak, Contemporary management Quarrerly, 2, 45-55 (2011)

12. L.T. Schoen, C. Teddlie, School Effectiveness and School Improvement, 19(2), 129153 (2008). https://doi.org/10.1080/09243450802095278

13. N.J. Zollers, M.Yu, A.K. Ramanathan, International Journal of Qualitative Studies in Education, 12(2), 157-174 (2010). https://doi.org/10.1080/095183999236231

14. A.Yu. Shemanov, D.E. Makaeva, Psychological Science and Education, 8(1), 24-34 (2016). https://doi.org/10.17759/psyedu.2016080103

15. T.M. Scott, K.L. Park, J. Swain-Bradway, E. Landers, International Journal of Behavioral Consultation and Therapy, 3(2), 223-235 (2007).

https://doi.org/10.1037/h0100800

16. V.G. Zakirova, E.L. Nikitina, International Journal of Environmental \& Science Education, 11(8), 2099-2111 (2016). https://doi.org/10.12973/ijese.2016.581a

17. Z.V. Polivara, M.P. Asylbekova, O.N. Budeeva, G.A. Zabirova, L.I. Kim, M.S. Dzhilkishieva, Pertanika Journal of Social Sciences \& Humanities, 25(S), 73-88 (2017) 